Int. J. Electrochem. Sci., 15 (2020) 1691 - 1703

\title{
In-Situ Fabrication of Tube Electrodes with Array Slits using Multi-Wire Electrochemical Machining
}

\author{
Tao Yang, Yongbin Zeng ${ }^{*}$ Xiaolong Fang, Yanliang Li
}

Jiangsu Key Laboratory of Precision and Micro-Manufacturing Technology, Nanjing University of Aeronautics and Astronautics, Nanjing 210016, China

*E-mail: binyz@nuaa.edu.cn

doi: $10.20964 / 2020.02 .52$

Received: 9 October 2019 / Accepted: 1 December 2019 / Published: 31 December 2019

\begin{abstract}
Wire electrochemical machining using an inner-jet electrolyte is an efficient cutting method of thick workpieces. A tube electrode with array slits is used, the electrolyte is sprayed directly from the array slits onto the machining gap and the electrolysis products are flushed out rapidly. An efficient and highprecision in-situ fabrication method is proposed for fabrication of the array slits structure of tube electrodes. Using electrochemical machining, the array slit structure is machined on a metal tube wall using multiple metal wires as the tool cathode. The effects of voltage, duty cycle, pulse frequency and electrolyte concentration on array slit width and depth are investigated experimentally, and optimal machining parameters obtained. A tube electrode with an average slit width of $218.6 \mu \mathrm{m}$ and depth of $270.7 \mu \mathrm{m}$ is successfully fabricated on stainless steel tube with an external diameter of $0.7 \mathrm{~mm}$ and the wall thickness of $0.15 \mathrm{~mm}$. The cutting experiment is completed on $20 \mathrm{~mm}$ thick stainless steel 304 using this fabricated tube electrode at a $5 \mu \mathrm{m} / \mathrm{s}$ feed rate. Three slits with an average width of $1.215 \mathrm{~mm}$ are successfully machined.
\end{abstract}

Keywords: tube electrode with array slits; situ fabrication; multi-wire ECM; WECM using a tube electrode

\section{$\underline{\text { FULL TEXT }}$}

(C) 2020 The Authors. Published by ESG (www.electrochemsci.org). This article is an open access article distributed under the terms and conditions of the Creative Commons Attribution license (http://creativecommons.org/licenses/by/4.0/). 